\title{
OCCURRENCE OF CAMPYLOBACTER SPECIES IN CHICKENS BY MULTIPLEX POL YMERASE CHAIN REACTION
}

\author{
ASMAA GAHLAN YOUSEEF ${ }^{1}$; A.I. IBRAHIM ${ }^{2}$; AMAL S.M. SAYED ${ }^{3}$ and \\ MONA M. SOBHY ${ }^{4}$ \\ ${ }^{1}$ Zoonoses Department, Faculty of Veterinary Medical, South Valley University. \\ ${ }^{2}$ Poultry Diseases Department, Faculty of Veterinary Medical, South Valley University. \\ ${ }^{3}$ Animal Hygiene and Zoonoses Department, Faculty of Veterinary Medical, Assiut University. \\ ${ }^{4}$ Reproductive Diseases Department, Animal Reproduction Research Institute, El-Haram, Giza.
}

Received: 14 December 2016; $\quad$ Accepted: 15 January 2017

\begin{abstract}
The genus Campylobacter is one of great importance to public health because it includes several species that may cause diarrhea. Poultry and poultry products are known as important sources of human campylobacteriosis. 225 samples were collected from (75) chickens including intestinal content (75), liver (75) and skin (75). The overall occurrence of Campylobacter jejuni and Campylobacter coli in chicken by PCR were (5.3\% \& $17.8 \%)$. Multiplex PCR targeting 23S rRNA specific for genus Campylobacter, hip O gene specific for C. jejuni and glyA gene specific for $C$. coli was used for the confirmation of phenotypically identified $C$. jejuni and $C$. coli isolates. It is concluded that PCR was determined to be more specific and rapid than biochemical tests.
\end{abstract}

Key words: Campylobacter, chickens, multiplex PCR.

\section{INTRODUCTION}

Campylobacter food borne illness incidence is considered the major cause of diarrhea in developed and developing countries. The high incidence of Campylobacter diarrhea, as well as its duration and possible sequelae, makes it highly important from a socio-economic perspective (World Health Organization, 2011). Campylobacter jejuni accounts for the majority of food borne Campylobacter enteritis in human, followed by Campylobacter coli and to a lesser extent by Campylobacter lari (Skirrow and Blaser, 2000). Campylobacter species are widely distributed in most warm-blooded animals. They are prevalent in food animals such as poultry, cattle, pigs, sheep, ostriches, shellfish and in pets, including cats and dogs (World Health Organization, 2011). The major routes of transmission in humans are consumption of contaminated or undercooked meat (especially poultry), (Center for Food Security and Public Health, 2013). Most people who become ill with campylobacteriosis have diarrhea, abdominal pain, and fever. The diarrhea may be bloody and can be accompanied by nausea and vomiting. Some infected persons do not have any symptoms. In persons with compromised immune systems,

Corresponding author: Dr. ASMAA GAHLAN YOUSEEF E-mail address: asmaagahlan@yahoo.com

Present address: Zoonoses Department, Faculty of Veterinary Medical, South Valley University.
Campylobacter occasionally spreads to the blood stream and causes a serious life-threatening infection (Centers for Disease Control and Prevention, 2013). Although most Campylobacter associated diarrhea is self-limited, complications can occur. One complication is Guillain-Barre' Syndrome (GBS), an acute, symmetric, ascending paralysis that is estimated to occur 30 times for every 100, 000 Campylobacter cases Wierzba (2008), and the case fatality ratio approaches $10 \%$ (Nachamkin et al. 1998). The aim of the current work was to isolate and characterize of Campylobacter isolates from chickens by conventional methods and confirm the results by using multiplex PCR.

\section{MATERIALS AND METHODS}

This study was carried out during the period between August 2014 and January 2016 in Reproductive Diseases Department, Animal Reproduction Research Institute El Haram, Giza.

1. Samples: 225 samples from (75) chickens including intestinal content (75), liver (75) and skin (75) were examined for Campylobacter from various markets in Giza Province.

\section{Samples preparation}

2.1. Chicken samples: 
Intestinal content: about $10 \mathrm{gm}$ of the intestinal content were homogenized in sterile thioglycolate broth and incubated at $42{ }^{\circ} \mathrm{C}$ For $48 \mathrm{hrs}$ under microaerobic condition $\left(5 \% \mathrm{O}_{2}, 10 \% \mathrm{CO}_{2}\right.$ and $85 \%$ $\mathrm{N}_{2}$ ) (Gebhart et al. 1985).

Liver and skin samples: twenty five grams from each incised skin or liver parts were aseptically transferred to a sterile tube containing thioglycollate enrichment broth for homogenization of the sample (Sallam, 2001).

3. Isolation of campylobacters species (Smibert, 1974): a loopfull from each sample were cultured directly onto thioglycollate broth medium for 24-72 hours in sterile tubes, and then a loopfull from each tube were cultured on modified Campylobacter blood free selective medium with antibiotics. All inoculated plates were incubated in anaerobic jar with kits which generates $\mathrm{CO}_{2}(10 \%), \mathrm{O}_{2}(5 \%)$ and nitrogen $(85 \%)$ in $37^{\circ} \mathrm{C}$ for 48 hours and were demonstrated daily for the characteristics colonies. Then the suspected colonies were purified on blood agar media with defibrinated blood sheep containing Campylobacter growth supplement for 24 hours. Suspected colonies were subjected to Gram staining and motility test.

4. Identification of the isolates: The suspected colonies were identified by:

4.1. Morphological identification: Suspected growing colony on the specific agar plates were examined carefully for their morphological characters according to Koneman et al. (1995). A single suspected colony was stained with Gram's stain to demonstrate the characteristics morphology of the isolates. Campylobacter species are Gram negative.

4.2. Motility (Smibert, 1974): Direct smear from 3 days old culture of Campylobacter organisms were made and examined under phase contrast microscope to demonstrate the corkscrew like motion characteristic to Campylobacter species.

4.3. Biochemical identification: The purified colonies were identified biochemically by the following tests:

4.3.1. Catalase production test: (Laing, 1960): A small amount of pure growth were placed onto the surface of a clean, dry glass slide by sterile loop then a drop of $3 \%$ hydrogen peroxide was added into a portion of colony on the slide. Production of gas bubbles indicating the production of catalase enzyme.

4.3.2. Nitrate reduction test: (Bryner and Frank, 1955): The isolated organisms were inoculated into nitrate broth. After 48hours 5 drops of solution A (sulfanilic acid+ acetic acid) and solution B ( $\alpha$ naphtylamin+ acetic acid) were added to the tube. A positive test is indicated by the development of red colour in 1-2 miutes.
4.3.3. Oxidase test: (El-Gohary, 1998): Oxidase activity was examined on filter paper with $1 \%$ aqueous solution of tetramethyl-p-phenyl-diaminedihydrochloride as a reagent. With a wooden loop a separate well grown colony will be picked up from a fresh culture medium ( 24 hours) and applied to the reaction on the filter paper.A positive reaction indicated by a violet colouration within 20-60 seconds at the contact point.

4.3.4. Urease test (El-Gohary, 1998): The isolated organisms were inoculated over the entire slope surface of the urease test tube and incubated at $37^{\circ} \mathrm{C}$ microaerophilic. Examination occurred after 4 hours and after overnight incubation. Urease positive cultures change the colour of the indicator to purple pink.

4.3.5. Hydrogen sulphide production, $\mathrm{H}_{2} \mathrm{~S}$ : (Bryner and Frank, 1955) By using lead acetate paper: The test conducted by suspending dried filter paper strips saturated with $10 \%$ lead acetate solution in tubes of thioglycollate medium and incubated at $37^{\circ} \mathrm{C}$ for $1-2$ days. Blackening of the paper is considered positive.

4.3.6. Temperature tolerance test: By using loopfull of diluted culture, streak a line across each of 3 plates of agar per isolate then inoculated and incubated one plate at $25^{\circ} \mathrm{C}$, one at $35-37^{\circ} \mathrm{C}$ and one at $42^{\circ} \mathrm{C}$ under microaerophilic atmosphere for 3 days. Positive reaction was indicated by the appearance of more growth than the initial inoculum after 72 hours of incubation.

4.3.7. Glycine tolerance test: (Chang and Ogg, 1971): The isolated organism was inoculated into semisolid thiglycollate tubes containing $1 \%$ glycine and incubated at $37^{\circ} \mathrm{C}$ for 5 days. Positive reaction was indicated by the appearance of specific colonies after 5 days of incubation.

4.3.8. Sodium chloride (Nacl) tolerance test: (Taul and Kleckner, 1968): Sodium chloride tolerance was determined by inoculation of the organism into semisolid thiglycollate medium containing $3.5 \% \mathrm{Nacl}$ then incubated at $37^{\circ} \mathrm{C}$ for 5 days. Positive reaction was indicated by the appearance of specific colonies after 5 days of incubation.

4.3.9. Hippurate hydrolysis test: (Carter, 1984): It is the only biochemical test to distinguish between C.jejuni and C.coli. In Wasserman test tube put 0.4 $\mathrm{ml}$ of thawed sodium hippurate then added large loopfull of isolated organism and emulsified. The culture was incubated for 2 hours at $37^{\circ} \mathrm{C}$. Then 0.2 $\mathrm{ml}$ of ninhydrin solution was added and the development of a deep purple color within 10-20 minutes indicated positive reaction.

\section{Molecular identification:}


5.1. DNA extraction: extraction of Campylobacter DNA from culture using (Thermo Scientific Gene Jet Genomic DNA Purification Kit\#K0721, \#K0722).

5.2. The primer sequences used for detection of Campylobacter: The primer sequence of Campylobacter targeting 23S rRNA gene were 5 TATACCGGTAAGGAGTGCTGGAG3' (forward) and 5'ATCAATTAACCTTCGAGCACCG 3` (reverse). While Species-specific primer targeting hip $O$ gene specific for $C$.jejuni (Wang et al., 2002) were 5 ACTTCTTTATTGCTTGCTGC3' (forward) and 5 GCCACAACAAGTAAAGAAGC3`(reverse).

Species-specific primer targeting glyA gene specific for C.coli (Wang et al., 2002) were 5 GTAAAACCAAAGCTTATCGTG3' (forward) and 5`TCCAGCAATGTGTGCAATG 3` (reverse).

5.3. DNA amplification of Campylobacter: Cycling conditions of the primers during PCR according to (Wang et al., 2002) with modifications. PCR amplification was performed using thermal cycler (Biometra) with the following programme: one cycle of $6 \mathrm{~min}$ at $94^{\circ} \mathrm{C}$. 35 cycles each consisting of $30 \mathrm{~s}$ at $95^{\circ} \mathrm{C}$ (denaturation), $30 \mathrm{~s}$ at $59^{\circ} \mathrm{C}$ (annealing), $30 \mathrm{~s}$ at
$72{ }^{\circ} \mathrm{C}$ (extension) and a final extension step at $72^{\circ} \mathrm{C}$ for $7 \mathrm{~min}$.

5.4. Detection of PCR products using Agarose gel electrophoresis (El-Adawy et al, 2012): The amplified PCR products were electrophosed in $1.5 \%$ agarose gel (Biometra).

The gel was photographed by a gel documentation system (Alpha Innotech).

\section{RESULTS}

The overall occurrence of Campylobacter was $24.9 \%$ (56 out of 225) which differentiated into C.jejuni 5.3 $\%$ (12 out of 225) and C. coli $17.8 \%$ (40 out of 225) by multiplex PCR. However the percentages of C.jejuni and C.coli in the samples of intestinal content were $4 \%$ ( 3 out of 75 ) \& $17.3 \%$ (13 out of 75), respectively. The percentages of C.jejuni and C.coli in the liver were $4 \%$ (3 out of 75 ) \& $22.7 \%$ (17 out of 75$)$, respectively. On the other hand the the percentages of C.jejuni and C.coli in the skin were $8 \%$ (6 out of 75$) \& 13.3 \%$ (10 out of 75 ), respectively as shown in (Table 1).

Table 1: Detection of Campylobacter by multiplex PCR in chicken

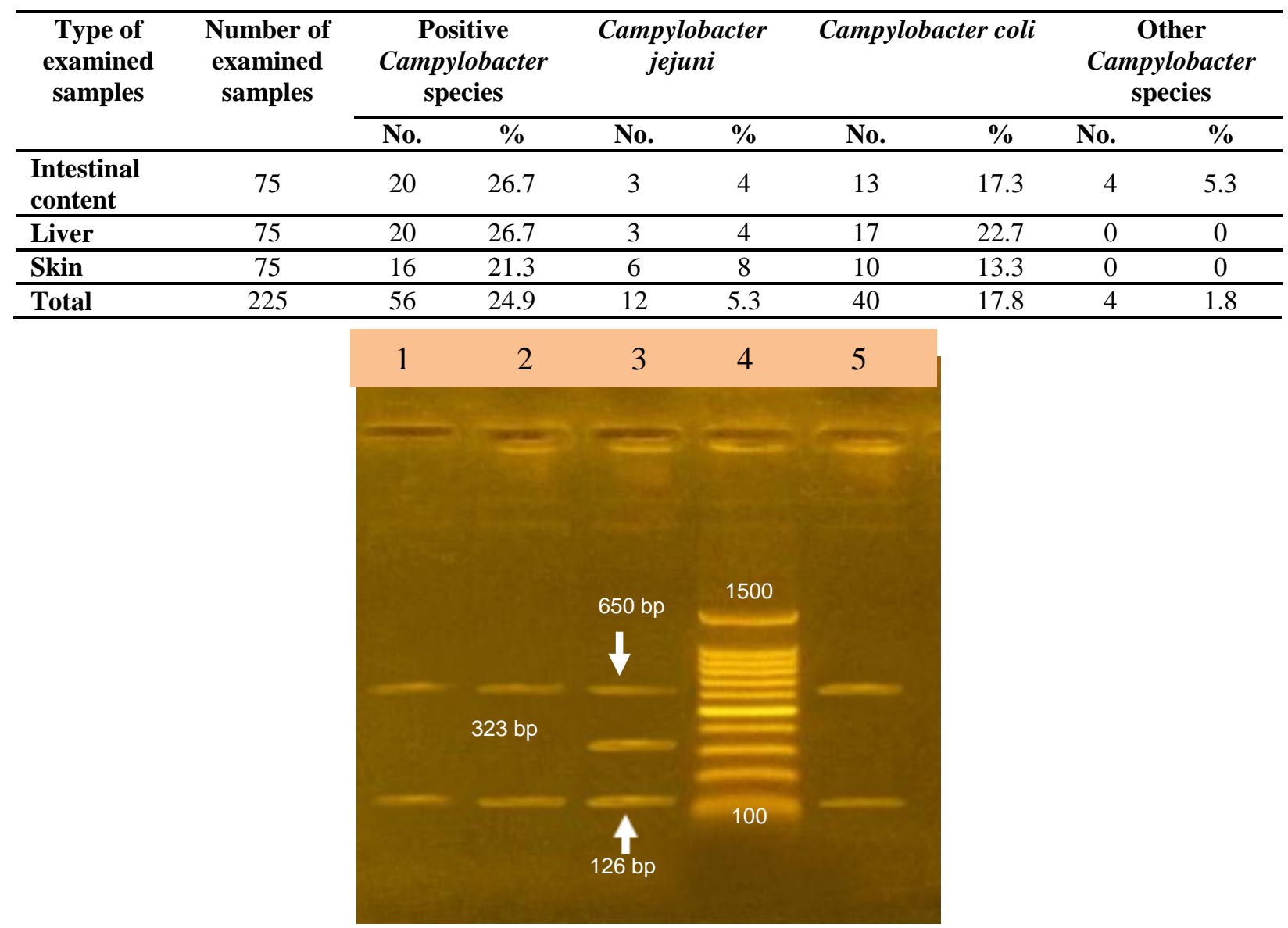

Figure (1): Multiplex PCR for detection of Campylobacter spp. (650 bp) using 23S rRNA gene, Campylobacter jejuni (323 bp) using hip $O$ gene and Campylobacter coli (126bp) using gly A gene. Lane 1, 2 and 5: positive for Campylobacter coli., Lane 3: Mixed infection for both $C$.jejuni and C.coli., and Lane 4: a 100bp molecular size marker. 


\section{DISCUSSION}

Data recorded in table (1) revealed that the overall prevalence of Campylobacter in chickens was $24.9 \%$. C. jejuni and $C$. coli were isolated from $5.3 \%$ and $17.8 \%$, respectively from chicken samples. Higher percentages $(80 \%, 56 \%, 76 \%, 68 \%, 44.4 \%$ and $48.7 \%$ ) of Campylobacter spp in chickens were obtained by Bardon et al. (2009); Ellerbroek et al. (2010); Weber et al. (2014); Sandberg et al. (2015); Osbjer et al. (2016) Schallegger et al. (2016) and respectively. C.jejuni was detected in $12(5.3 \%)$ of the examined chicken samples. Higher percentages of C.jejuni $(22 \%, 17 \%, 36 \%$ and $73.3 \%)$ in chickens were obtained by Ansari-Lari et al. (2011), Henry et al. (2011), Khalifa et al. (2013) and Schallegger et al. (2016), respectively. Lower percentage of C. coli $(2.7 \%)$ was obtained by Bardon et al. (2009). However higher percentages $(53.3 \%, 30 \%$ and $32 \%)$ of $C$. coli were obtained by Schallegger et al. (2016), Henry et al. (2011) and Ansari-Lari et al. (2011). Generally, the variation in Campylobacter species isolation rate between different studies could be attributed to different possible reasons, such as, type of examined samples, location, climate factors, hygienic measures and isolation as well as identification techniques (Jorgensen et al. 2011 and Chatur et al., 2014).

Campylobacter species were isolated from 20 $(26.7 \%)$ out of the examined intestinal samples collected from chickens. Nearly similar percentage (26.3\%) of Campylobacter species was isolated from the intestine by Bai et al. (2014). However lower percentages $(19.7 \%$ and $4.8 \%)$ were obtained by Oyarzabel et al. (1995) and Hofshagen and Kruse (2005), respectively. Higher isolation rates (45.9\%, $28 \%$ and $83.3 \%$ ) were obtained by Atanssova and Ring (1998), Bartkowiak-Higgo et al. (2006) and Kramer et al. (2000), respectively. C.jejuni and C.coli were isolated from $4 \%$ and $17.3 \%$, respectively from intestinal samples of chickens. The incidence of C.jejuni in the intestine was $3(4 \%)$ (Table 6). Higher percentage $(36.3 \%)$ was obtained by Kang et al. (2006). On the other hand the percentage of C.coli was $13(17.3 \%)$ (Table 6). Lower percentage (1.8\%) of C.coli was obtained by Zweifel et al. (2008). While higher percentages $(26.4 \% \& 18.5 \%)$ of C.coli were obtained by Kang et al. (2006) and Sallam (2007).

The overall occurrence of Campylobacter in liver samples of chickens was $(26.7 \%)$. \%). Higher percentage $(53.3 \%)$ of Campylobacter species in liver was obtained by Stoyanchev (2004). While lower percentages $(15.5 \%, 24 \%$ \& $21 \%)$ of Campylobacter species in liver were obtained by Boukraa et al. (1991); Bartkowiak-Higgo et al. (2006) and Vashin et al. (2009) respectively. The isolation rate of $C$. coli isolated from the liver was higher than $C$. jejuni. It has been noted that liver hygiene highly concerns food safety mainly in two directions. First, there is huge risk of many people to be infected after consuming insufficient cooked liver with Campylobacter. Besides, the contaminated poultry liver is a potential source for transferring Campylobacter in further stages of poultry processing (Vashin et al. 2009). This result is important in food hygiene circle since it could lead to high risk of infection among consumers who might eat insufficiently-cooked chicken liver. In addition, the liver, if packed inside the carcasses, becomes a good vehicle for Campylobacter spread inside the body cavity the (Stoyanchev 2004).

The isolation rate of Campylobacter from skin samples was $16(21.3 \%)$ of which, $8 \%$ were identified as $C$. jejuni and $12.3 \%$ were $C$. coli (Table 1). Higher percentages $(47.5 \%, 46.6 \%$, and $30.8 \%)$ of Campylobacter in skin of chickens were obtained by Garin et al. (2012); Saad (2014) and Abd El- Tawab et al. (2015), respectively. The higher incidence of Campylobacter jejuni in skin samples and Campylobacter coli in liver samples of chickens may be due to rupture of intestine during processing activities. Chicken skin provides suitable microenvironment for the survival of Campylobacters due to accumulation of water which increases the surface area available for bacterial contamination (Chantarapanont et al., 2003).

\section{CONCLUSION}

It is concluded that the relatively high proportion of the examined chicken is contaminated by Campylobacter spp. and that consumption of undercooked or cooked contaminated poultry products consider a possible risk for consumers. Contamination of poultry by Campylobacter is a significant risk factor of human campylobacteriosis.

\section{REFERENCES}

Abd El-Tawab, A.A.; Ammar, A.M.; Ahmed, H.A.; El Hofy, F.I. and Hefny, A.A. (2015): Bacteriological and Molecular Identification of Campylobacter Species in Chickens and Humans, at Zagazig City, Egypt. Benha. Veterinary Medical Journal, 28(1): 17-26.

Ansari-Lari, M.; Hosseinzadeh, S.; Shekarforoush, S.S.; Abdollahi, M. and Berizi, E. (2011): Prevalence and risk factors associated with Campylobacter infections in broiler flocks in Shiraz, southern Iran. International journal of food microbiology; 144(3): 475-9.

Atanassova, V. and Ring, C. (1998): Campylobacter species in the surroundings of poultry meat 
production. Incidence and chinolone resistance, Zentralbl. Hyg. Umweltmed, 200 (5-6): 542-552.

Bai, Y.; Cui, S.; Xu, X. and Li, F. (2014): Enumeration and characterization of Campylobacter species from retail chicken carcasses in Beijing, China. Key Lab of Food Safety Risk Assessment, Ministry of Health, China National Centre for Food Safety Risk Assessment, Beijing, China. Foodborne Pathog Dis.; 11(11): 861-7.

Bardon, J.; Kolar, M.; Cekanova, L.; Hejnar, P. and Koukalova, D. (2009): Prevalence of Campylobacter jejuni and its Resistance to Antibiotics in Poultry in the Czech Republic. Zoonoses Public Health. 56: 111-116.

Bartkowiak-Higgo, A.J.; Veary, C.M.; Venter, E.H. and Bosman, A.M. (2006): A pilot study on post-evisceration contamination of broiler carcasses and ready-to-sell livers and intestines (mala) with Campylobacter jejuni and Campylobacter coli in a high-throughput South African poultry abattoir. J. S. Afr Vet Assoc.; 77(3): 114-9.

Boukraa, L.; Messier, S. and Robinson, Y. (1991): Isolation of Campylobacter from livers of broiler chickens with and without necrotic hepatitis lesions. Avian Dis; 35(4): 714-7.

Bryner, J.H. and Frank, A.H. (1955): A preliminary report on identification of Vibrio fetus. J. Vet. Res. 16: 76-78.

Carter, G.R. (1984): Diagnostic procedures in veterinary Bacteriology, Mycology. Campylobacter. Charles C., Thomas Publisher Springfield Illinions, USA Chapter 6: 59-71.

Center for Food Security and Public Health (2013): Zoonotic Campylobacteriosis, Campylobacter Enteritis, Vibrionic Enteritis, vibriosis. http:// www.cfsph.iastate.edu/IICAB/.

Centers for Disease Control and Prevention (CDC) (2013): Campylobacter. How do people get infected with this germ? Atlanta, GA: US Department of Health and Human Services.http://www.cdc.gov/ nczved/ divisions/dfmbd/diseases/campylobacter/.

Chang, W. and Ogg, J.F. (1971): Transduction and mutation to glycine in Vibrio fetus. Am. J. Vet. Res., 32: 649-653.

Chantarapanont, W.; Berrang, M. and Frank, J.F. (2003): Direct microscopic observation and viability determination of Campylobacter jejuni on chicken skin. J. Food Prot., 6: 22222230.

Chatur, Y.A.; Brahmbhatt, M.N.; Modi, S. and Nayak, J.B. (2014): Fluoroquinolone resistance and detection of topoisomerase gene mutation in Campylobacter jejuni isolated from animal and human sources. Int. J. Curr. Microbiol. App. Sci., 3(6) 773-783.

El-Adawy, H.; Hotzel, H.; Tomaso, H.; Neubauer, H. and Hafez, H.M. (2012): Elucidation of colonization time and prevalence of thermophilic Campylobacter species during turkey rearing using multiplex polymerase chain reaction. Poult. Sci.; 91(2):454-9.

El-Gohary, A.H. (1998): Prospective studies on campylobacteriosis in human and animals in contact. Assiut Vet. Med. J., 38: 192-202.

Ellerbroek, L.I.; Lienan, J.A. and Klein, G. (2010): Campylobacter species in broiler flocks at farm level and the potential for crosscontamination during slaughter. Zoonoses Public Health. 57 (7-8): 81- 88.

Garin, B.; Gouali, M.; Wouafo, M.; Perchec, A.; Thu, P.M.; Ravaonindrina, N.; Urbès, F.; Gay, M.; Diawara, A.; Leclercq, A.; Rocourt, J. and Pouillot, R. (2012): Prevalence, quantification and antimicrobial resistance of Campylobacter species on chicken neck-skins at points of slaughter in 5 major cities located on 4 continents.Int. J. Food Microbiol., 157: 102107.

Gebbhart, C.; Edmonds, P.; Word, G.; Kurtz, H. and Bernner, D. (1985): Campylobacter hyointestinalis spp: A new species of Campylobacter found in the intestine of pigs and other animals. J. Clin. Microbiol .21:715720.

Henry, I.; Reichardt, J.; Denis, M. and Cardinale, E. (2011): Prevalence and risk factors for Campylobacter species in chicken broiler flocks in Reunion Island (Indian Ocean). Prev. Vet. Med, 100 (1): 64-70.

Hofshagen, M. and Kruse, H. (2005): Reduction in flock prevalence of Campylobacter species in broilers in Norway after implementation of an action plan. J. Food. Prot, 68(10): 2220-2223.

Jorgensen, F.; Ellis-Iversen, J.; Rushton, S.; Bull, S.A.; Harris, S.A.; Bryan, S.J.; Gonzalez, A. and Humphrey, T.J. (2011): Influence of Season and Geography on Campylobacter jejuni and C. coli Subtypes in Housed Broiler Flocks Reared in Great Britain. Appl. Environ. Microbiol., 77(11): 3741.

Kang, Y.S.; Cho, Y.S.; Yoon, S.K.; Yu, M.A.; Kim, C.M.; Lee. J.O. and Pyun, Y.R. (2006): Prevalence and antimicrobial resistance of Campylobacter jejuni and Campylobacter coli isolated from raw chicken meat and human stools in Korea. J. Food. Prot, 69(12): 2915-23.

Khalifa, N.O.; Radwan, M.E.I. and Sobhy, M.M. (2013): Molecular Study of Campylobacter jejuni Isolated from Chicken, Dairy Cattle and Human to Determine Their Zoonotic Importance. Global Veterinaria., 10 (3): 332336.

Koneman, E.W.; Allen, S.D.; Janda, W.M.; Schreckenberger, P.C. and Winn, W.C. (1995): Introduction to diagnostic Microbiology $5^{\text {th }}$ ed. Lippincott. Company, Philadelphia, (USA). 
Kramer, J.M.; Frost, J.A.; Bolton, F.J. and Warring, D.R. (2000): Campylobacter contamination of raw meat and poultry at retail sale: identification of multiple types and comparison with isolates from human infection. J. Food. Prot. 63(12): 1654-1659.

Laing, A.J. (1960): Vibrio fetus infection of cattle, food and Agr. Organ. FAO. Publication No.51.Rome, Italy.

Nachamkin, I.; Allos, B.M. and Ho, T. (1998): Campylobacter species and Guillain-Barré syndrome. Clin. Microbiol. Rev., 11: 555-567.

Osbjer, K.; Boqvist, S.; Sokerya, S.; Chheng, K.; San, S.; Davun, H .; Rautelin, H. and Magnusson, $U$. (2016): Risk factors associated with Campylobacter detected by PCR in humans and animals in rural Cambodia. Epidemiol Infect. 23:1-10.

Oyarzabal, O.A.; Conner, D.E. and Hoerr, F.J. (1995): Incidence of Campylobacter in the intestine of avian species in Alabama. Avian Dis.; 39(1): 147-51.

Saad, A.E.M. (2014): Zoonotic Importance of Campylobacteriosis at Sharkia Province. M.V.Sc thesis, Zoonoses Dep., Fac. Vet. Med., Zagazig Univ.

Sallam, K.I. (2001): Campylobacter contamination in retailed chicken carcasses from Mansoura, Egypt, and its relation to public health. Alex. J. Vet. Sci., 17 (1).

Sallam, K.I. (2007): Prevalence of Campylobacter in chicken and chicken by-products retailed in Sapporo area, Hokkaido, Japan. Food Control; 18(9-18):1113-1120.

Sandberg, M.; Sorensen, L.L.; Steenberg, B.; Chowdhury, S.; Ersboll, A.K. and Alban, L. (2015): Risk factors for Campylobacter colonization in Danish broiler flocks. Poult. Sci. 94, 447-453.

Schallegger, G.; Muri-Klinger, S.; Brugger, K.; Lindhardt, $\quad$ C.; John, L.; Glatzl, M.; Wagner, M. and Stessl, B. (2016): Combined Campylobacter jejuni and Campylobacter coli Rapid Testing and Molecular Epidemiology in Conventional Broiler Flocks. Zoonoses Public Health.

Skirrow, M.B. and Blaser, M.J. (2000): Clinical aspects of Campylobacter infection. In Campylobacter, Nachamkin, I. and Blaser,
M.J. (2nd Eds.), Washington, DC: American Society for Microbiology. pp: 69-88.

Smibert, R.M. (1974): Campylobacter: In Bergey s Manual of Determinative Bacteriology $8^{\text {th }}$ Ed., Baltimore, Williams and Wilkins 207-211.

Stoyanchev, T.T. (2004): Detection of Campylobacter using standard culture and PCR of 16S rRNA gene in freshly chilled poultry and poultry products in a slaughter house. Trakia Journal of Sciences. 2(3): 59-64.

Taul, L.K. and Kleckner, A.I. (1968): Fluorescent antibody studies of Vibrio fetus staining characteristics in semen, preputial exudates and pure culture. Am. J. Vet. Res., 29: 711715.

Vashin, I.; Stoyanchev, T.; Ring, Ch and Atanassova, $V$. (2009): Prevalence of Campylobacter spp in frozen poultry giblets at Bulgarian retail markets. Trakia Journal of Sciences, 7 (4): 55 57.

Wang, G.; Clark, C. and Taylor, T. (2002): Colony multiplex PCR assay for identification and differentiation of Campylobacter jejuni, $C$. coli, C. lari, C.upsaliensis and C. fetus subsp. fetus. J. Clin. Microbiol; 40: 4744-7.

Weber, R.; Auerbach, M.; Jung, A. and Glünder, G. (2014): Campylobacter infections in four poultry species in respect of frequency, onset of infection and seasonality. Berl Munch Tierarztl Wochenschr. 127(7-8): 257-66.

Wierzba, T.F.; Abdel-Messih, I.A.; Gharib, B.; Baqar, S.; Hendaui, A.; Khalil, I.; Omar, T.A.; Khayat, H.E.; Putnam, S.D.; Sanders, J.W.; Ng, L.K.; Price, L.J.; Scott, D.A. and Frenck, R.R. ( 2008): Campylobacter infection as a trigger for Guillain-Barre' syndrome in Egypt. PLoS One 3 (11): e3674. https://www. ncbi.nlm.nih.gov/pubmed/19002255.

World Health Organization (2011): Campylobacter Fact sheet $\mathrm{N}^{\circ} 255$ October. http://www.who.int/ mediacentre/factsheets/fs $255 / \mathrm{en} /$.

Zweifel, C.; Scheu, K.D.; Keel, M.; Renggli, F. and Stephan, R. (2008): Occurrence and genotypes of Campylobacter in broiler flocks, other farm animals, and the environment during several rearing periods on selected poultry farms. International Journal of Food Microbiology; 125(2): 182-7. 


\section{مدي تواجد الكامبيلوباكتر في الاجاج باستخدام تفاعل البلمرة المتسلسل}

\section{أسعاء جهلان يوسف ، أحمد إبراهيم أحدل، أمل سبا محد ، مني محمد صبحي}

Email: asmaagahlan@yahoo.com Assiut University web-site: www.aun.edu.eg

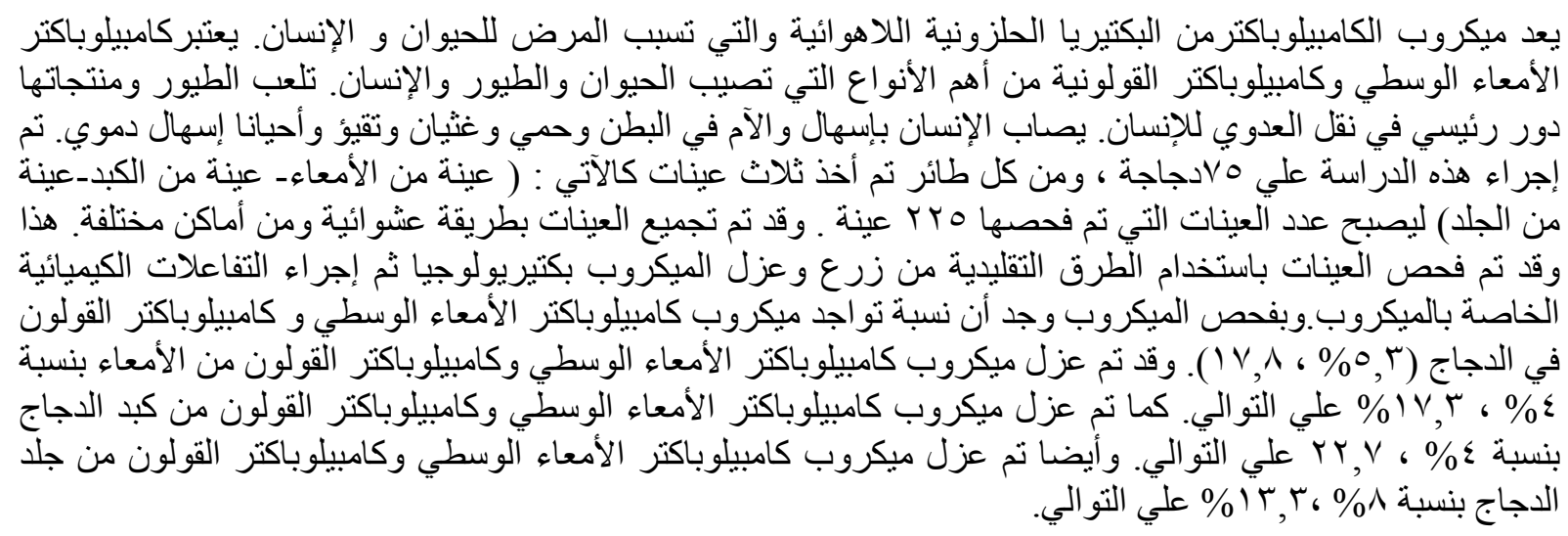

